\title{
Scientific Evidence Between The Use of Oral Contraceptives And Thrombotic Events: An Integrative Review
}

\author{
Pablo Luiz Santos Couto ${ }^{*}$, Alba Benemérita Alves Vilela ${ }^{2}$, Antônio Marcos Tosoli Gomes ${ }^{3}$, Luana Costa \\ Ferreira ${ }^{4}$, Maria Luisa Pereira Neves ${ }^{4}$, Samantha Souza da Costa Pereira ${ }^{5}$, Cleuma Sueli Santos Suto ${ }^{6}$, \\ Dejeane de Oliveira Silva ${ }^{7}$, Cinoélia Leal de Souza ${ }^{8}$ and Magno Conceição das Merces ${ }^{9}$ \\ ${ }^{1}$ Nurse Master in Nursing, Higher Education Center of Guanambi, Guanambi, Brazil \\ ${ }^{2}$ Nurse, PhD in Nursing. State University of Southwest Bahia. Jequié, Brazil \\ ${ }^{3}$ Nurse PhD in Nuarsing, State University of Rio de Janeiro. Rio de Janeiro, Brazil
}

${ }^{4}$ Nursing student, Higher Education Center of Guanambi, Brazil

${ }^{5}$ Nurse Master in Public Health, Higher Education Center of Guanambi, Brazil

${ }^{6}$ Nurse PhD in Nursing and Health, State University of Bahia, Brazil

${ }^{7}$ Nurse PhD in Nursing and Health, State University of Santa Cruz, Brazil

${ }^{8}$ Nurse PhD in Nursing and Health, Higher Education Center of Guanambi, Brazil

${ }^{9}$ Nurse PhD in Health Sciences, State University of Bahia, Brazil

*Corresponding author: Pablo Luiz Santos Couto. Master in Nursing, Higher Education Center of Guanambi, Brazil

\section{ARTICLE INFO}

Received: 慧 February 05, 2020

Published: 㓞 February 12, 2020

Citation: Pablo Luiz Santos Couto, Alba Benemérita Alves Vilela, Antônio Marcos Tosoli Gomes, Luana Costa Ferreira, Maria Luísa Teixeira Neves, et al. Scientific Evidence Between The Use of Oral Contraceptives And Thrombotic Events: An Integrative Review. Biomed J Sci \& Tech Res 25(4)-2020. BJSTR. MS.ID.004221.

Abbreviations: CVA: Cerebrovascular Accidents, CAPES: Health Personnel Higher Education, BVS: Virtual Health Library, EE: Ethinyl Estradiol, VTE: Venous Thromboembolism

\section{ABSTRACT}

Introduction: Women with chronic diseases are at higher risk of worsening their clinical condition, with the possibility of developing thrombotic events, when they make prolonged use of hormonal oral contraceptives.

Objective: To identify in the literature the scientific evidence on thrombotic events resulting from the use of oral contraceptives by women.

Material and Method: Integrative literature review, using the databases of the Virtual Health Library and the Journal of the Coordination for the Improvement of Higher Education Personnel as a research source, using the search terms "contraceptives" and "hormonal contraceptives" and "peripheral venous thrombosis". With this search, 156 publications were initially found, after making the selection, 13 scientific articles were included in the review. The texts were submitted to semantic content analysis.

Results: Two categories were highlighted, which were discussed concurrently: the use of oral contraceptives: clinical and theoretical aspects; association between the use of oral contraceptives and thrombotic events.

Conclusion: Thrombotic events occur in most women who make long-term use of hormonal oral contraceptives, especially those whose composition is estrogen. It will help professionals to adequately guide women in choosing the contraceptive method, considering the complications.

Descriptors: Contraceptives; Adverse events; Thrombosis; Reproductive Health; Sexual Health; Women's Health. 


\section{Short Communication}

Even thoughsociety has madeprogress inwomen's achievements in relation to sexual and reproductive rights, especially in accessing contraceptive methods, there is still difficulty in accessing health services and failure in guidelines, resulting in complications and repercussions for women's health [1-2]. Hormonal contraceptives are the most efficient reversible contraceptive methods available and the most widely used in the world. It is believed that in developed countries, around $18 \%$ of women who are married or united at any time, use oral contraceptives, this proportion being $75 \%$ in developing countries, which represents millions of women in use worldwide, including the Brazil [3]. Thus, this high prevalence of the use of hormonal contraceptives, especially oral ones, makes it necessary to monitor possible adverse events that happen due to prolonged use such as peripheral venous thrombosis and its complications [1]. In this context, women with a predisposition to cardiovascular diseases and who use hormonal contraceptives have been at high risk for arterial thrombosis, and this risk is directly related to the estrogen present in the composition of these drugs.

In Europe and developed countries, about 13\% of cases of Cerebrovascular Accidents (CVA) in women aged 20 to 44 years are associated with the use of oral hormonal contraceptives [4]. The frequency of adverse effects in the use of contraceptives can be minimized by choosing the contraceptive method according to the individual health condition [5]. But, for this to occur, it is necessary for professionals to know the possible effects, which is still little discussed in the clinical practices of health professionals [1]. Therefore, as a research question, what scientific evidence was pointed out in the literature about thrombotic events resulting from the prolonged use of hormonal oral contraceptives? To help answer such a question, this study aimed to identify in the literature the scientific evidence on thrombotic events resulting from the use of oral contraceptives by women.

\section{Material and Methods}

It was an integrative literature review, based on the stages of choosing the theme; elaboration of the work plan, with the definition of the descriptors; identification and location in the databases; compilation and file, with the elaboration of the summary table of the results found; analysis, using an analysis method for interpretation. This type of article does not require submission to the ethics and health research committee. For data collection, the integrated search system of the Virtual Health Library (BVS) database was used, which included the search in the MEDLINE and LILACS databases, and the Periodical Base of the Coordination for the Improvement of Health Personnel Higher Education (CAPES), which includes PUBMED and Google Scholar, in order to find publications of scientific articles related to the theme of study from 2008 to 2018. The "integrated search method" was used to search the databases, in "all indexes" and "all sources", which allows for a broad search integrating several databases and a detailed search in titles, abstracts and texts. The words used for the search were: contraceptives and hormonal contraceptives and peripheral venous thrombosis.

From the results found with the search: "oral contraceptives" AND "adverse events" and "peripheral venous thrombosis"; 156 results were found, opposed to perform the full and available text filter, language: Portuguese, year: 2008 to 2018, type of document: article. Among the 34 publications 15 included the study period. 02 articles were excluded due to repetition, totaling 13 articles, which were available as full texts, which were included in the study analysis (Figure 1). Subsequently, we proceeded with the analysis of semantic content that allowed to identify the similarities and divergences in the interpreted results from the identification of the units of meaning and decoding of the codes, followed by the survey of the semantic similarities of the interpreted content, which showed two categories of analysis.

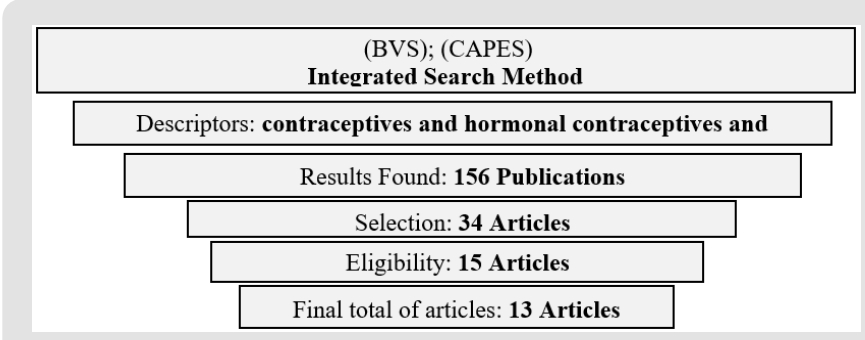

Figure 1: Detailed flowchart of the systematic selection of the articles included in the study.

\section{Results}

From the results found, it was observed that the arguments used by the authors of the reviewed articles and their respective scientific evidence, about the relationship between the continued use of oral contraceptives and the occurrence of thrombotic events, associated with the effects recurrently addressed in the literature, which will be portrayed in the discussion of the two categories After an exploratory and thorough reading of the publications and the identification of the semantic approximation of the results of the articles that most appeared in the reviewed articles, a table was organized with the distribution of the articles according to the theme that were most present in the results and discussion of the revised publications (Table 1).

Table 1: Distribution of articles for the composition of the analysis categories on "Oral Contraceptives" AND "Adverse Events", from 2008 to 2018, after classification of CAPES publications, BVS and Journals.

\begin{tabular}{|c|c|}
\hline Analysis Categories & Reference /Articles \\
\hline $\begin{array}{c}\text { The use of oral contraceptives: clinical and } \\
\text { theoretical aspects }\end{array}$ & $3,5,9,10,13,14$ \\
\hline $\begin{array}{c}\text { Association between the use of oral } \\
\text { contraceptives and thrombotic events }\end{array}$ & $2,4,6,7,8,11,12$ \\
\hline
\end{tabular}




\section{Discussion}

Oral hormonal contraceptives can be classified according to their hormonal composition, dosage and type of hormone and also as to the generation that is related to the dosage and amount of estrogen hormone combined or not [6]. Society over the years has undergone cultural changes that collaborate and influence sexuality, especially in the prevention and care of sexual and reproductive health [2]. It is important to emphasize that in Brazil the use of such contraceptives has been increasing since 2006, about $80 \%$ of women of childbearing age use some reversible method, and because this accessibility becomes easy and the choice for the irreversible method is significantly reduced [7]. In this context, a study concluded that the method most adopted by women was the combined oral hormonal (ethenyl estradiol associated with cyproterone or drospirenone), and the most prevalent method was the monthly one, also noted that the majority of women interviewed made this choice without taking into account side effects, mainly weight gain and migraine reduced [8].

In another study carried out with 240 patients, 120 from the private network and 120 from the public network, the authors showed that stenyl-a-tradiol was the most prescribed hormone $(48.3 \%)$ in both networks, with no difference between the frequency of side effects [9]. However, like any medication, contraceptives also have some contraindications, the most frequent of which are hypertension, smoking, hormonal diseases, and predisposition to thrombosis. There is a need to review integrated care for possible contraindications existing in Brazilian women, during sexual and reproductive health guidance and treatment [10]. Oral contraceptives have in their formulation the Estrogen Derivative, Ethinyl Estradiol (EE), and this synthetic hormone alters the coagulation mechanism causing an increase in thrombin formation, therefore, the risk of Venous Thromboembolism (VTE). In addition, EE also increases clotting factors and decreases in protein $\mathrm{S}$ and antithrombin. Progestogens combined with these contraceptives also have risks for venous thromboembolism, such as those of third generation (gestodene, desogestrel) which increases the risk to two times that of second generation (levonorgestrel) [11].

Female sex hormones have an effect on the cardiovascular system, because blood vessels have estrogen and progesterone receptors in all their constituent layers, thus increasing thrombin generation, which will lead to a state of hypercoagulability11. Research has shown that women, when using these hormones, are more likely to develop venous thromboembolism, since oral contraceptives act on the cardiovascular system, however it is emphasized that this association is more evident with inappropriate use and self-medication, which maximizes other risk factors, such as genetics, and guidance from health professionals on the use of 5 [12]. Thus, the decision on the choice of contraceptive method should be based on the assessment of all potential risks and benefits of the method and, above all, on the woman's personal and family history3. Therefore, screening for hereditary thrombophilia in women with a positive history is recommended, and these women should not use any combined oral contraceptive5, [13]. It was shown that venous thrombosis has multiple causes, which are associated with a hereditary risk factor (in this case V Leiden, which is a more common hereditary venous thromboembolic risk factor) and an acquired risk factor (use of combined oral contraceptives) [14].

\section{Conclusion}

It is concluded that the adverse effects resulting from the use of hormonal oral contraceptives have been the object of continuous investigation and since hormonal contraception is the most used method for preventing unplanned pregnancy, the literature has shown that the possible relationships between the use of hormone therapy with the risk of developing cardiovascular, cerebrovascular problems and pulmonary thromboembolism, resulting from peripheral venous thromboembolism, has a direct association with long-term use. It is suggested that other studies to deepen the cause and effect relationships, between the use of hormonal oral contraceptives and genetic predispositions, since these were the gaps and limitations found in the reviewed studies. Thus, the search for the treatment of hormonal contraception in sexual and reproductive health programs in family planning is increasingly frequent, so the preparation and knowledge of the health professional is essential for women in choosing the most appropriate to their needs.

\section{References}

1. (2013) Ministry of Health (BR) Health Care Secretariat. Department of Primary Care. Sexual health and reproductive health. Brasília, DF.

2. Almeida APF, Assis MM (2017) Side effects and physiological changes related to continued use of contraceptive. Rev Eletrôn Atualiza Saúde 5(5): 85-93.

3. Couto PLS, Gomes AMT, Pereira AB, Carvalho JS, Silva JK, et al. (2019) Use of hormonal contraceptives by prostitutes: correlation with markers of social vulnerability. Acta Paul Enferm 32(5): 507-513.

4. Olsen JM, Lago TD, Kalckmann S, Alves MC, Escuder MM (2018) Young women's contraceptive practices: a household survey in the city of Sao Paulo, Brazil. Cad Saúde Public 34(2): e00019617.

5. Pandovan FT, Freitas G (2015) Oral contraceptives associated with the risk of deep vein thrombosis. Braz Jour Surgery Clinical Research 9(1): 73-77.

6. Ventura R, Malta JSM, Lyra AFC, Danda DMR, Urbano LCV (2009) Association of chromatic changes and use of oral contraceptives. Arq Bras Oftlmol 72(1): 62-64.

7. Giglio MR, Andrade LC, Daher GM, Ribeiro MO, Albernaz MA (2015) Hormonal contraception from the perspective of medical students: another challenge for Brazilian medical education? Rev Bras Educ Med 39(4): 502-506.

8. Steckert APP, Nunes SF, Alano GM (2016) Oral hormonal contraceptives: Use and risk factors in university students. Arq Catarin Med 45(1): 7892.

9. Gomes PD, Zimmermmann JB, De Oliveira LMB, Leal KA, Gomes ND, et al. (2011) Hormonal contraception: a comparison between public and private health care patients. Cien Saude Colet 16(5): 2453-2460. 
10. Corrêa DAS, Felisbino Mendes MS, Mendes MS, Malta DC, Velasquez Melendez G (2017) Factors associated with contraindicated use of oral contraceptives in Brazil. Rev Saúde Public 51(1): 1-10.

11. Braga DC, Moraes LJA, OliveiraC, Trevisan G (2015) Relationship of oral contraception and the risk of deep vein thrombosis in women in the reproductive period. Anais de Medic 1(1): 1-2.

12. Lobo RA, Romão F (2011) Female sex hormones and deep vein thrombosis. Angiol Cirurgia Vasc 7(4): 208-214

ISSN: 2574-1241

DOI: $10.26717 /$ BJSTR.2020.25.004221

Pablo Luiz Santos Couto. Biomed J Sci \& Tech Res

(C) This work is licensed under Creative Commons Attribution 4.0 License

Submission Link: https://biomedres.us/submit-manuscript.php
13. Mariano GZ, Schimidt MM, Maturana MA, Quevedo E, Negri B, et al. (2015) Impact of oral contraceptive use on the characteristics and clinical evolution of women undergoing primary percutaneous coronary intervention. Rev Bras Cardiol Invasiva 23(3): 190-194.

14. Maia HO (2015) Deep vein thrombosis in an upper limb in a woman taking oral contraceptives and with hereditary thrombophilia - Factor V Leiden. Rev Port Med Geral Fam 31(esp): 121-124.

$\begin{array}{ll}\text { BIOMEDICAL } & \text { Assets of Publishing with us } \\ \text { RESEARCHES } & \text { - Global archiving of articles } \\ & \text { - Immediate, unrestricted online access } \\ & \text { - Rigorous Peer Review Process } \\ & \text { - Authors Retain Copyrights }\end{array}$

